Revista Temas Socio Jurídicos

Vol. 37 No $^{\circ} 74$ Enero - Junio de 2018

pp. $68-84$

ISSN: 0120-8578

ISSN electrónico: 2590-8901

\title{
LA “CONTRADICCIÓN FUNDAMENTAL” EN EL MOVIMIENTO CRITICAL LEGAL STUDIES
}

\section{Leidy Lizeth Flórez Sandoval ${ }^{1}$}

Recibido: Abril 23 de 2018

Aprobado: Mayo 31 de 2018

\section{RESUMEN.}

Como heredero del realismo jurídico estadounidense de principios del siglo XX, el movimiento Critical Legal Studies -en adelante CLSenarbola la bandera de la indeterminación del Derecho. Sin embargo, va más allá de la tesis realista y sostiene que tal no obedece a un mero problema lingüístico o formal sino a una verdadera manifestación de una "contradicción" o una serie de contradicciones sustantivas que subyacen al liberalismo, entendido como tradición ideológica, económica y política sobre la que se ha construido el modo de vida estadounidense.

El objeto de este trabajo es describir en qué consiste esta "contradicción" desde la perspectiva de los miembros de CLS, así como de los autores que, tanto en Europa como en América Latina, la han analizado -si así ha sido. Para lograrlo será menester previamente: i) trazar un esquema general que permita comprender, a grandes rasgos, lo que CLS es y defiende; ii) abordar los trabajos "paradigmáticos" al interior del movimiento CLS sobre la contradicción, particularmente los producidos por Duncan Kennedy; iii) revisar si en la literatura europea y latinoamericana esta idea ha tenido repercusión y, de ser así, cómo se ha efectuado su análisis.

Palabras clave: Critical Legal Studies. Contradicción Fundamental. Liberalismo.

1 Abogada de la Universidad Industrial de Santander. Discente del Máster Oficial en Estudios Avanzados en Derechos Humanos, Universidad Carlos III de Madrid. Correo electrónico: leez29hotmail.com 


\section{ABSTRACT.}

As the heir of the early 20th century American legal realism, the Critical Legal Studies movement - from now on CLS - flies the flag of the indeterminacy of law. However, it goes beyond the realist thesis and argues that it does not obey a simple linguistic or formal problem but a true manifestation of a "contradiction" or a series of substantive contradictions that underlie the liberalism, understood as tradition ideological, political and economic over which has been built the way of American life.

The object of this work is to describe what is this "contradiction" from the perspective of members of CLS, as well as the authors who, both in Europe and in Latin America, have analyzed it - if this has been-. To achieve this purpose will be necessary previously: i) to draw a general scheme that allows to understand, broadly, what CLS is and defends; (ii) to study the 'paradigmatic' works to the interior of the CLS movement about the contradiction, particularly those produced by Duncan Kennedy; (iii) to check if in the European and Latin American literature this idea has had impact, of being like that, how itsanalysis has been carried out.

Key words: Critical Legal Studies. Fundamental Contradiction. Liberalism.

\section{A “CONTRADIČÃO FUNDAMENTAL" NO MOVIMIENTO ÇRITICAL LEGAL STUDIES}

\section{RESUMO}

Como herdeiro do realismo jurídico norte-americano do início do século XX, o movimento Critical Legal Studies -doravante CLS- levanta a bandeira da indeterminação do Direito. No entanto, vai além da tese realista e argumenta que não obedece a um mero problema linguístico ou formal, mas sim a uma verdadeira manifestação de uma contradição ou de uma série de contradições substantivas subjacentes ao liberalismo, entendido como uma tradiçã̃o ideológica, econômica e política na qual o modo de vida americano foi construído.

O presente estudo tem por objetivo descrever essa contradição do ponto de visto dos membros do CLS e dos autores que, na Europa e na América Latina, a analisaram. Para isso será necessário previamente: i) elaborar um esquema geral que permita compreender, em linhas gerais, o qué o CLS defende; ii) abordar os trabalhos paradigmáticos do movimento CLS sobre a contradição, particularmente os que foram produzidos por Duncan Kennedy; iii) analisar se, na literatura européia e latino-americana, essa ideia teve impacto e, em caso afirmativo, como essa análise foi feita. 
Palavras-chave: Critical Legal Studies. Contradição fundamental. Liberalismo.

\section{INTRODUCCIÓN}

Los análisis críticos del Derecho, en boga durante gran parte del siglo $\mathrm{XX}$, suelen recibir el calificativo de "menos racionales» en los textos de estudio de Filosofía del Derecho, según los cuales, tradicionalmente, son dos las grandes teorías filosóficas que se han encargado del estudio del fenómeno jurídico: el iusnaturalismo y el iuspositivismo, así como múltiples interpretaciones que viran más o menos entre uno y otro.

Este trabajo es la respuesta al sentimiento de indignación personal que me produjo la idea de la «irracionalidad» endilgada al pensamiento crítico, originada en la tradición dualista moderna, que elimina la posibilidad de un espectro mayor en que es dable analizar el fenómeno jurídico, lo que conlleva la necesidad de ahondar en el estudio de teorías que no se enmarquen e una y otra esquina, no necesariamente para afiliarse a ellas, sino para ampliar el espectro acerca de lo que es y debería ser el Derecho en una sociedad como la actual. Las teorías críticas constituyen un aporte rico en multidisciplinariedad a las que deberíamos acercarnos un poco más.

En este orden de ideas, los estudios críticos del derecho estadounidenses, así como los análisis que desde América Latina y Europa se han realizado en esta misma senda, han contribuido, por ejemplo, al análisis crítico de la formación que estamos recibiendo en las facultades de Derecho y cómo la misma, no sólo es resultado sino a la vez origen de una "clase social», la de los abogados, que prolongan esquemas de poder propios del sistema económico y social que subyace a todo ordenamiento en el hemisferio occidental ${ }^{2}$.

Este trabajo no abordará el estudio acerca del rol de las universidades y la formación profesional en Derecho; ahondará más bien en la forma en que una de estas vertientes críticas considera el fenómeno jurídico, cómo se denuncia la contradicción inherente al propio sistema económico y social en que se sustenta el Derecho, denuncia que sin duda constituye un elemento de partida para analizar, por ejemplo, el verdadero rol de la judicatura, así como el de los y las profesionales en derecho en el estudio y resolución de casos difíciles, cuya comprensión resulta cada vez más necesaria.

\section{2. ¿QUÉ ES Y QUÉ PRETENDE CLS? UNA VISIÓN PANORÁMICA.}

El rasgo característico de las teorías críticas del Derecho propias de 
la última mitad del siglo $\mathrm{XX}^{3}$, tanto en Europa como en el continente americano ${ }^{4}$, es la conciencia acerca de la futilidad que representa formular el interrogante acerca de qué es el Derecho o cuál es su contenido. Su compromiso ideológico lleva a plantear otro tipo de preguntas que, autores como Nuñez Vaquero (2010), han sintetizado en dos: "¿Qué podemos hacer en el mundo como juristas? ¿Cómo podemos mejorarlo?”.

Dentro de las corrientes críticas que han intentado resolver estos interrogantes no resulta exagerado afirmar que la más llamativa es la de los Critical Legal Studies estadounidense. El contexto geográfico, político e histórico en el que surgió, así como las particularidades de su "funcionamiento interno", hacen que quizá sea la más difícil de comprender, especialmente para quien se haya formado en la tradición del derecho continental europeo. Su complejidad irradia todos los aspectos de su "vida". La diversidad de intereses intelectuales y temas de estudio, la alusión a trabajos provenientes de las más variopintas disciplinas del conocimiento, la consecuente utilización de metodologías de estudio social y jurídico igualmente diversas, y la propia estructura de su producción intelectual, generan más resquemor que interés en ciertos sectores de corte tradicional dentro de los teóricos del Derecho.

Un acercamiento a CLS, por más general que sea, lleva ineludiblemente a escudriñar en su origen histórico. Tanto para los autores que lo integran como para quienes se han dedicado a su análisis ${ }^{5}$ no hay duda de que la piedra angular sobre la que descansa la estructura del movimiento fue puesta en la primera Conference on Critical Legal Studies celebrada en la Facultad de Derecho de la Universidad de Wisconsin en el año 1977, aunque la piedra en sí misma se descubrió en la década de los 60 en la universidad de Yale, donde un grupo de profesores (entre los que destaca, para los efectos de este estudio, David Trubek) miembros del Law \& Society Movement, con posturas críticas en un escenario social revolucionado por el movimiento contracultural, organizó, gracias a la financiación de la Agencia para el Desarrollo Internacional, un Reading group sobre "filosofía de la ciencia social" como base para una teoría social del derecho. En este grupo participaron estudiantes y futuros cofundadores del movimiento CLS, entre los que cabe destacar a Duncan Kennedy y Mark Tushnet (Gordon, 2009).

En 1973, tras ser "despedido" de Yale junto con otros colegas de posturas disidentes frente al establishment, David Trubek obtuvo una plaza en la

3 Para una introducción al estudio de las corrientes críticas más representativas en el hemisferio occidental ver Pérez Lledó (1996).

4 En adelante, cuando se haga referencia a América se ha de asociar con la realidad geográfica que conglomera a tres subcontinentes: Norte, Centro y Sur, y no como sinónimo de los Estados Unidos, uno de los tantos estados que lo conforman.

5 Una referencia inevitable en este trabajo y en muchos otros que se han escrito en lengua castellana sobre el movimiento es la tesis doctoral, posteriormente editada como libro, del profesor Pérez Lledó (1996), de la que se han tomado varias de las referencias históricas reseñadas en este aparte. Ver, de igual forma, Kennedy (1992) y Gordon (2009). 
Facultad de Derecho de la Universidad de Wisconsin, donde casualmente terminó trabajado también Mark Tushnet. Desde allí mantuvo contacto estrecho con sus compañeros docentes y algunos alumnos, entre los que destaca Duncan Kennedy -convertido en profesor de la Facultad de Derecho de la Universidad de Harvard y quien había integrado una red en este centro universitario de la que hacía parte Robert. M. Unger-, lo que dio como resultado una pequeña red de colaboración y difusión académica de la que surgió la idea de organizar la conocida conferencia en estudios críticos del Derecho que congregó a académicos de todo el país y que generó en definitiva la conformación de los CLS (Pérez Lledó, 1996).

Según resalta Núñez Vaquero (2010), tres vertientes metodológicas estuvieron presentes en ese primer encuentro: i) La sociología empírica de Law \& Society Movement (D. Trubek, L. Friedman, P. Selznick y P. Nonet, profesores de sociología de la Universidad de Yale); ii) la crítica ideológica del Derecho estructuralista-realista, con fuerte influencia, posteriormente del neomarxismo de cierto sector de la Escuela de Fráncfort (D. Kennedy, M. Horwitz y R. Unger, K. Klare y M. Kelman, profesores los tres primeros e investigadores los últimos de la Universidad de Harvard); iii) marxismo ortodoxo (Mark Tushnet) y serán estas las líneas que marquen el rumbo investigativo del movimiento. Sin embargo, Law \& Society Movement fue objeto de duras críticas en las sesiones iniciales, debido a su conexión estrecha con los contenidos y el estilo de la nueva ortodoxia post realista de los años 50 y 60 contra la que precisamente dirigía la mayor parte de sus críticas el nuevo movimiento, lo que explica el por qué, sin duda, el momento en el cual surge CLS tal como se conoce hoy día fuese la segunda conferencia celebrada en Madison a finales del mismo año 1977, a la cual no asistieron los representantes más connotados de esta vertiente, y que fuera en ese momento en el que quedaron definidas las líneas de trabajo teórico y los intereses más o menos comunes entre los integrantes del movimiento (a los que se irán agregando, tal como resalta Kennedy (1992), durante las décadas de los 80 y 90 posturas postmodernas deconstructivismo- y los Critical Race Theory y Feminist Jurisprudence).

Esta multiplicidad de visiones y estrategias metodológicas constituye parte del vasto universo CLS que, pese a la disolución, en los años 90 (Pérez Lledó, 1995), de las conferencias anuales que venían celebrando desde su fundación, han mantenido vivo el movimiento con una vasta producción intelectual a lo largo y ancho del territorio estadounidense y con colaboraciones e influencias notorias en algunos teóricos europeos y latinoamericanos que han cursado estudios de posgrado en las universidades donde más se ha afincado el movimiento -destacándose sin duda la Facultad de Derecho de Harvard-.

Del anterior recuento, y pese al temor de caer en generalizaciones contraproducentes, pero con la certeza de la necesidad de una caracterización de este tipo, puede afirmarse que CLS es, palabras más, palabras menos, un nicho de conocimiento y de acción política presente 
en las principales facultades de Derecho estadounidenses ${ }^{6}$ "iniciad[o] y renovad[o] periódicamente por profesoras, profesores, estudiantas y estudiantes" (Kennedy, 1992, 283), ideológicamente de "izquierda" 7 , para quienes el Derecho es, en esencia, política -law is politics- ${ }^{8}$ y que por ello abordan el estudio del fenómeno jurídico como fenómeno político, lo que permite comprender el carácter fuertemente interdisciplinar y particular de sus estudios, que beben, fundamentalmente, de la sociología, la antropología, la historia, la psicología y los estudios literarios, y que metodológicamente viran desde el estructuralismo hasta las tesis deconstructivistas.

En línea con el postulado antes mencionado, y quizá debido a él, el movimiento ha prestado un especial interés ${ }^{9}$ al sistema de enseñanza del Derecho en Estados Unidos como reproductor de los esquemas de la ideología moral, política y económica dominante que favorece ciertos temas o contenidos curriculares sobre otros, así como sistemas de jerarquías y promoción tanto de estudiantes como de profesores ${ }^{10}$. Para CLS, si se admite que la facultad de Derecho condiciona la formación jurídica de los abogados y las abogadas en cierta concepción del mundo y de sus problemas, es posible comprender, por una parte, la forma en que abogados y abogadas, jueces y juezas, académicos y académicas, e, incluso, teóricos y teóricas del Derecho ejercen la profesión y, por otro, que al interpretar el Derecho vigente -entendido como tal el derecho positivo- se opte por esa postura ideológica.

Junto con su vertiente más política e ideológica, otra "ala" del movimiento, más jurídica (la denominada estructuralista-realista), ha retomado la tesis realista de la indeterminación del Derecho y la ha llevado a un nivel teorético superior, para afirmar que el derecho es indeterminado precisamente por la contradicción inherente a la ideología en que éste se afinca, que no es otra que el liberalismo ${ }^{11}$.

6 Aunque también se identifican como integrantes del movimiento profesionales de campos diferentes al derecho, tal como se observa en la literatura de Critical Race Theory o Feminist Jurisprudence, en la que la producción proviene en gran medida de estudiosos de otras disciplinas sociales.

7 “[CLS] Es de izquierdas, y sin embargo es profundamente crítico con el marxismo». Ya tenemos algo más: su componente marxista -que sólo es uno más- es el del neomarxismo crítico occidental que desarrolló la "crítica marxista al marxismo»: Lukács, Gramsci o la Escuela de Frankfurt. Más que el marxismo, es el espíritu de la Nueva Izquierda americana de los años sesenta lo que marca sus señas de «identidad colectiva»" (Pérez Lledó, 1995, p. 138).

8 Esta primera característica común del movimiento es esencial para comprender lo que se abordará en adelante.

9 Son varias las líneas de estudio que han desarrollado autores del movimiento desde distintas perspectivas del pensamiento. Desde análisis sociológicos del derecho, pasando por estudios feministas o de race theory, entre otros muchos.

10 Para profundizar sobre este tema véase Kennedy, D., 2009, pp. 549-578

11 Sobre la que se profundizará más adelante. 
En síntesis, CLS es: i) un movimiento esencialmente local surgido en los Estados Unidos como una crítica frente a la forma de abordar el fenómeno jurídico; ii) académico, no una manifestación o panfleto político al interior de las Facultades de Derecho. Ello no significa que sus integrantes se asuman como ideológicamente neutrales, en modo alguno lo son, pero tampoco son necesariamente activistas, ni CLS es un movimiento de acción social (Kennedy, 2009, p. 580)); iii) con una influencia interdisciplinar muy fuerte, pese a que la mayoría de sus miembros sean juristas; iv) una plataforma crítica frente a la supuesta neutralidad del Derecho -que inicia desde su enseñanza hasta su aplicación al caso concreto-, que no es más que una fachada tras la que se esconde un conflicto entre polos opuestos y contradictorios que subyace a la ideología en que se sustenta el Derecho y que permite que en ciertos contextos una misma norma jurídica sirva para justificar varias tomas de postura -estructuralismorealismo-; v) una crítica pos ilustrada a la "gran teoría" que traiciona la idea de complejidad y la contingencia social y congela la posibilidad de imaginar órdenes alternativos. Es así como opta por teoría local en contraposición -prácticas teóricas a pequeña escala (Pérez Lledó, 1995, p. 138).

\section{LA CRÍTICA INTERNA AL DERECHO. EL REALISMO JURÍDICO NORTEAMERICANO Y "INDETERMINANCY THESIS".}

La denominada "revuelta contra el formalismo jurídico" de tipo jurisprudencial $^{12}$ reinante en Estados Unidos desde mediados del siglo XIX se sustentó en gran medida en el realismo jurídico, cuyos miembros notorios ${ }^{13}$ fueron, en esencia, abogados $-\mathrm{y}$, a su vez, profesores universitarios- que en muchos casos ejercían la profesión ante y en los tribunales, lo que explica en gran medida su visión sociologista, no normativista, del Derecho y permite comprender el porqué del ataque frontal a lo que consideraron "excesos del formalismo".

El realismo se caracterizó, a grandes rasgos, por

su escepticismo acerca de la fuerza determinante de los precedentes jurisprudenciales, por creer que los jueces pueden fallar siempre lo que se les antoja y que, por lo tanto, deciden los casos a partir de sus intereses de clase o caprichos pasajeros. (Gordon, 2009, p. 521)

12 Tradición que se "basada en los principios del Estado de Derecho, de la división de poderes y de la subordinación del juez a la ley, y de otro lado, encontraba su expresión característica en un nuevo método de enseñanza que tenía como presupuesto implícito una concepción sistemática del Derecho. Me refiero al case method, que estudiaba el Derecho tomando como base, noya los precedentes, es decir, la ratio decidendi de las decisiones anteriores, sino una selección preparada al efecto de casos particularmente importantes alos que se atribuía un carácter normativo". (Treves, 1988, pp. 81-82).

13 Jerome Frank, Mark Llewellyn, Roscoe Pound, se encuentran entre los autores más conocidos de esta corriente de pensamiento. 
El escepticismo frente a la "fuerza determinante de los precedentes jurisprudenciales" $y$, en un sentido más general, ante las reglas (y también -o sobre todo- ante los hechos, en cierto sector de estudiosos que defienden esta postura) sin duda constituye el punto de partida para comprender los análisis del movimiento respecto al Derecho, que podrían sintetizarse, siguiendo a Llewelyn, tal como fuera citado por el profesor Renato Treves (1988, p. 98), así: i) Concepción del Derecho como un proceso en continuo movimiento, que va de la mano con la tesis de la creación judicial del derecho; ii) la concepción del derecho como un medio para alcanzar determinados fines sociales; iii) la concepción de la sociedad como un ente que fluye más rápido que el Derecho; iv) divorcio temporal entre ser y deber ser para fines investigativos; v) desconfianza hacia las reglas y los conceptos jurídicos tradicionales, que pretenden describir lo que los tribunales y las personas hacen en realidad -escepticismo frente a las reglas-; vi) desconfianza adicional hacia la teoría que afirma que las formulaciones de reglas prescriptivas son el factor determinante en las decisiones judiciales; vii) desconfianza en las reglas verbalmente simples que engloban situaciones de hecho diversas y complejas, que lleva a la creencia en la utilidad de agrupar casos y situaciones jurídicas en categorías estrechas, más de lo que había sido en el pasado; viii) valoración de cualquier parte del Derecho con base en sus efectos; ix) insistencia en que el ataque sistemático y programático sobre los problemas del Derecho, siguiendo las líneas anteriores, es necesario.

En ese orden de ideas, dos fueron las banderas o temas de interés de estudio en el seno del realismo. Por una parte, uno eminentemente crítico frente al formalismo clásico y su ilusión de certeza y predecibilidad del Derecho, que llevó a la formulación de la tesis de la indeterminación lingüística del Derecho y la consecuente de la discrecionalidad judicial; por otra, como derivado o consecuencia del anterior, uno de tipo constructivo, en el que se vio abocado un importante sector del movimiento y del que derivan dos importantes instrumentos: el policy analysis ${ }^{14}$ y la investigación sociológica empírica. Procederemos a explicar brevemente en qué consiste teóricamente cada uno de estos proyectos.

El Derecho -entendido aquí como el sistema de reglas positivas vigenteses indeterminado. Esta afirmación tuvo importantes repercusiones fácticas para el momento en que se difundió, porque denunció una situación que trastocaba el tradicional sistema de equilibrio de poderes. El juez, según el realismo, actuaba discrecionalmente en la mayoría de los casos puestos bajo su consideración, precisamente a causa de la indeterminación ya denunciada. Así las cosas, el Derecho era, esencialmente, la decisión que tomaba éste.

Pero ¿En qué consiste exactamente la indeterminación del Derecho? Para dar respuesta a este interrogante es menester precisar que la característica ya denunciada del derecho se avizora, según el realismo, desde dos

14 Traducido frecuentemente como: "Análisis de conveniencia política" (Gordon, 2009, p. 503) 
niveles: El primero, como vaguedad lingüística “intrínseca” en las reglas y conceptos jurídicos, debida a la textura abierta de los términos generales del lenguaje natural en que se plasman unas y otros, y su consecuente carácter flexible y abierto. Esta indeterminación, inherente a la regla o el concepto individualmente considerado, se multiplica cuando para el caso concreto hay varias reglas aplicables relevantes, ya que se presentan múltiples puntos potenciales de indeterminación -legal, no nos referimos aquí a la tesis de la indeterminación de los hechos- que se manifiesta a la hora de resolver un caso concreto.

Por su parte, el segundo nivel se ubicaba externamente y tenía que ver con el hábito de las reglas de "salir a cazar por parejas" que contienen soluciones contradictorias entre sí pese a que una y otra pueden perfectamente aplicarse al caso concreto. Esta segunda tesis fue la que retomó el movimiento del CLS para extenderlo en su argumentación.

La indeterminación así vista acarrearía, según los realistas, dos consecuencias. La primera, que en la práctica no era posible -contrario a lo que pregonara el formalismo- predecir el sentido de las decisiones judiciales en casos similares, por lo que el case method perdía toda razón de ser, y la segunda, directamente relacionada con la anterior, que en la decisión relativa a la aplicación de la o las reglas el juez acudiría necesariamente a criterios externos, ubicados en un nivel superior, y a introducir con ello una categoría intermedia entre la o las reglas escritas y los hechos a los que se pretenden aplicar, que es en el que virtualmente se suele encontrar el juzgado o el tribunal de justicia.

A propósito de esta segunda consecuencia surgió el proyecto constructivista de los realistas, encaminado a dotar de mayor certeza al Derecho y reducir con ello su grado de indeterminación. La propuesta metodológica fue de tipo instrumental y tuvo dos vertientes: el recurso al policy analysis como estrategia para extraer los principios y objetivos de policy sociales que están detrás de las reglas y con ello determinar la respuesta que según estos objetivos era aplicable, por idoneidad, al caso concreto y, complementario de lo anterior, el recurso a la ciencia social de corte empírico como método de análisis social.

CLS retomó el primero de los proyectos. Fue desde un principio especialmente crítico con el segundo, dado que, si bien tuvo inicialmente acogida, posteriormente no demoró en convertirse en un instrumento igualmente inocuo, en una especie de aplicación formalista del Derecho (Gordon, 2009, p. 521). Sin embargo, en los aspectos sustanciales sí tomó elementos para extender su tesis. Pretender dotar de certeza y disminuir con ello en gran medida el grado de indeterminación del derecho recurriendo a los principios y a los policies sociales conduce a la consideración de cuestiones genuinamente políticas y morales ${ }^{15}$ que sólo traslada de nivel el problema de la indeterminación, no lo resuelve. Este es sin duda el aporte de CLS a la discusión sobre el tema, y consiste en 
(...) extender el tema realista de los "paired oppositions" mostrando cómo estos conflictos no sólo aparecen en el sistema de reglas, sino también en el sistema de policies y principios en los que aquellas se inspiran, lo que lleva nuevamente al problema que quizá sea central para los realistas: el juez ha de tomar opciones que no están dictadas por el Derecho.

Parte de la "solución" al problema de la indeterminación comienza, según lo considera un importante sector de CLS, por reconocer que la contradicción en los niveles normativo y político-moral son meras manifestaciones de la oposición existente entre los presupuestos sobre los que descansa la ideología que subyace al ordenamiento jurídico, al menos en los Estados Unidos: el liberalismo.

Del anterior planteamiento puede desprenderse la siguiente consideración, común a las diversas vertientes que al interior del movimiento se han desarrollado en torno a esta tesis:

(...) filosófica, moral y políticamente el Derecho contemporáneo está simultáneamente comprometido con polos opuestos de presupuestos e ideales irreconciliables, y los conflictos en los materiales jurídicopositivos no son sino manifestaciones de esas contradicciones situadas en niveles mucho más profundos. En último término, lo que subyace son las contradicciones del "pensamiento liberal», entendido éste en un sentido amplísimo, a veces prácticamente coextensivo con la visión del hombre y del mundo y con la forma de racionalidad que llamamos «moderna» o «ilustrada». (Pérez Lledó, 1992, p. 141)

Algunos de los pares de opuestos que han sido evidenciados por los integrantes de CLS al interior del liberalismo serían, en términos bastante vagos, y según la clasificación realizada por Pérez Lledó (1995), los que a continuación de enuncian: "contradicción fundamental", individualismo vs. Altruismo (Kennedy); la "antinomia de la razón y del deseo" y la "antinomia de las reglas y los valores" (Unger); la contradicción entre el "discurso intencionalista" y el "discurso determinista" (Kelman), esencialmente.

Así las cosas,

El problema del liberalismo consistiría, en este sentido, en que en su seno estarían presentes dos lógicas o espíritus contrastantes, lo que llevaría a la imposibilidad de determinar de manera neutral el contenido del derecho. Esta tensión, sin embargo, no produce un puro caos sin sentido; antes bien, los juristas expertos son capaces de prever con cierta fiabilidad qué y cómo van a decidir los tribunales. (Núñez Vaquero, 2010, p. 420)

Conforme lo expuesto, de los análisis sobre los pares de opuestos atrás mencionados hemos de profundizar en el primero. La escogencia 
de las posturas de Kennedy tiene que ver, por un lado, con el carácter más o menos completo de sus estudios y un mayor acceso a bibliografía seleccionada y, por otro, con lo que representaron y siguen significando esos trabajos al interior del movimiento.

\section{LA "CONTRADICCIÓN FUNDAMENTAL" EN LA PRODUCCIÓN INTELECTUAL DE DUNCAN KENNEDY.}

La expresión "contradicción fundamental" aparece plasmada por primera vez en The Structure of Blackstone's Commentaires (1979), un estudio realizado por Kennedy sobre los comentarios de un jurista inglés del siglo XVIII que sirvió como material de enseñanza y síntesis del pensamiento jurídico tradicional en el mundo jurídico anglosajón de la época. A partir de la revisión de los contenidos temáticos de los comentarios, Kennedy pretendió, y así lo explicitó en la introducción de su trabajo, iniciar

(...) al lector en un método de comprensión del significado político del pensamiento legal, un método que podría ser llamado estructuralista, o fenomenológico, o neomarxista, o los tres juntos. (Kennedy, 1979, p. 211-212)

Para Kennedy "las relaciones con otros son al mismo tiempo necesarias para e incompatibles con nuestra libertad" (Kennedy, 1979, p. 213). De ahí que la "contradicción fundamental" aluda a "nuestros sentimientos dolorosamente contradictorios acerca del estado actual de las relaciones entre las personas en nuestro mundo social" (Kennedy, 1979, p. 213). Va, por ende, más allá de la existencia de dos polos opuestos -liberalismo y altruismo- tiene que ver más con la forma en que concebimos y nos relacionados con el mundo exterior; esa y no otra es la auténtica contradicción lógica, que persiste en la medida en que disminuye el grado de abstracción del análisis para terminar reflejándose, implícitamente, en la forma y contenido de reglas y estándares normativos del derecho positivo estadounidense.

En este punto del discurso sin duda vendría bien una explicación del propio autor sobre lo ya expuesto, que se encuentra en los Commentaires en las siguientes palabras, traducidas por Pérez Lledó (1995), así:

He aquí una formulación inicial de la contradicción fundamental: la mayoría de los participantes en la cultura jurídica americana creen que el objetivo de la libertad individual es al mismo tiempo dependiente de e incompatible con la acción coactiva colectiva que es necesaria para alcanzarlo. Los otros (familia, amigos, burócratas, tipos culturales, el Estado) son necesarios para constituirnos como personas: ellos nos proporcionan la materia [stuff] de nuestro yo, y nos protegen de forma crucial contra la destrucción. Incluso cuando nos parece que estamos más solos, los demás están con nosotros, incorporados a nosotros mediante procesos lingüísticos, cognitivos y emotivos que son como cuestión simplemente biológica, aspectos colectivos de nuestra individualidad. 
Además, no siempre estamos solos. A veces tenemos experiencias de fusión con otros, en grupos de dos o incluso de dos millones, y es una experiencia más buena que mala (...). Pero a la vez que nos constituye y nos protege (...) el universo de los otros nos amenaza con aniquilarnos y nos impulsa hacia formas de fusión que son claramente más malas que buenas. Innumerables sometimientos, grandes y pequeños abandonos del yo a los otros, son el precio de cuanta libertad experimentemos en sociedad.

Se observa en el fragmento citado que la idea de una "contradicción fundamental" se encuentra en niveles profundos, y que fue la culminación de los planteamientos acerca de la oposición intrínseca en el sistema moral, político y económico denominado liberalismo en que se sustentaba el derecho positivo estadounidense vigente para entonces, que, según esta tesis, oscilaba entre el opuesto individualista y el altruista, y que fuera planteada y ampliamente expuesta en Forma y Sustancia en la adjudicación del Derecho Privado estadounidense $(1976)^{16}$, de modo que no puede comprenderse un texto sin el otro, son mutuamente complementarios.

Una lectura de los dos trabajos permite comprender al lector lo que de manera somera se ha dicho acerca del movimiento. En primer lugar, son textos con un alto contenido de estudio jurídico más que filosófico - que dentro del movimiento tiene una notable excepción en los planteamientos de Unger en Conocimiento y Política, enfocados, uno de un texto histórico, que hace parte de la tradición jurídica angloamericana (Commentaires) y otro que analiza el derecho privado estadounidense, particularmente en lo que podríamos denominar "derecho de obligaciones" (Forma y sustancia); en segundo lugar, el análisis se realiza a partir de una descripción general de los objetos estudiados, con los que se van introduciendo ciertas categorías que llevan a la construcción posterior de una argumentación que permite evidenciar cómo tras las reglas o estándares -principios- de derecho positivo se esconden pares de opuestos que llevan al planteamiento de la existencia de una única contradicción ideológica, propia del liberalismo, entre el individualismo -la opción de libertad del yo- y el altruismo -el bienestar de los otros-

Ya hemos dicho que el trabajo en el que Kennedy desarrolla su pensamiento respecto a la contradicción entre individualismo y altruismo es Forma y Sustancia. Este trabajo es un interesante análisis jurídico-político del derecho privado estadounidense, escenario en el que Kennedy se movía como pez en el agua, dado su desempeño profesional como docente en esta rama del Derecho. Lo que expuso el autor en este trabajo se puede sintetizar en los términos que siguen.

El análisis de las normas o directivas jurídicas debe realizarse partiendo de

16 Existen varias traducciones del original disponibles en la página web del profesor Kennedy http://duncankennedy.net/bibliography/chrono.html. Para este trabajo se utilizaron simultáneamente las versiones en lengua castellana -parcial- e italiana, las cuales se encuentran enlistadas en la bibliografía. 
sus dos componentes: uno formal y uno sustancial. La cuestión de forma en que deben emitirse las normas permite distinguir entre reglas -con las cualidades de generalidad, rigidez, precisión, imparcialidad, abstracción, enlistadas por Mesa (2002) - y estándares - más flexibles, aplicables ad hoc-. Asimismo, existen posturas morales y políticas sustantivas opuestas con una retórica propia a la hora de abordar los problemas: individualismo Vs. Altruismo. Las posturas relativas a la forma tienden a corresponderse con la sustancia: los estándares suelen justificar contenidos altruistas mientras las reglas hacen lo propio con actitudes individualistas. El conflicto entre ambos opuestos está en una situación de bloqueo, no parece haber una línea clara que defina cuándo se está ante una postura u otra, no hay polos definidos, se admiten elementos de una y otra, se presenta una relación de contingencia entre los dos. Por contera, el uso que se haga de reglas o principios en favor de uno u otro polo dependerá de los objetivos sustantivos que se persigan.

¿Qué significa entonces reconocer la existencia de la contradicción fundamental? Según Kennedy, en primer lugar, permite avanzar en la caracterización de los conflictos morales y prácticos que subyacen al Derecho, aunque no los disminuya. En segundo lugar, permite reconocer que no es posible equilibrar valores ni reglas individualistas y altruistas según el principio de equidad, excepto en "el sentido tautológico de que podemos, de hecho, decidir si tenemos que hacerlo"(AA.VV., ${ }^{17}$ no hay equilibrio, es precisamente el tipo de unidad de medida abstracta que está excluida por la contradicción. En tercer lugar, en cualquier sistema jurídico las actitudes individualistas -especialmente manifiestas al apelar a la aplicación de reglasresponden a interés concretos que se erosionan y pueden perder el terreno ganado. El individualismo no es un triunfo ya logrado. El papel del abogado, del juez, del jurista frente a un sistema en el que este polo es el dominante resulta fundamental para lograr posturas altruistas, sin que ello comporte en modo alguno el caer en ideologías extremas, como el totalitarismo, al que tanto se le teme en el contexto estadounidense. Finalmente, este reconocimiento permite a su vez asimilar que el juez no puede tener un comportamiento eminentemente racional; no puede evitar que en "el momento de la verdad" cambie de modalidad para tomar la decisión. Quizá este último reconocimiento se sintetice en el siguiente enunciado: "en términos de individualismo, el juez ha comenzado súbitamente a actuar de mala fe. En términos de altruismo, se ha encontrado a sí mismo"18

\section{5. ¿ES EXPORTABLE LA TESIS DE LA CONTRADICCIÓN FUNDAMENTAL? PROPUESTAS DESDE EL EXTERIOR.}

Previo a cualquier análisis, y lejos de pretender volver a lo ya tocado en páginas anteriores, preciso es atender a un rasgo característico de CLS, consistente en "(...) la búsqueda dirigida a establecer contactos en otros países con aquellos grupos que puedan tener actitudes e inquietudes

17 AA.VV., Sociología Jurídica, Teoría y Sociología del Derecho en Estados Unidos. op. cit., p. 187

18 KENNEDY, D., Forma y Sustancia... op. cit., p. 185-187 
similares y con los que mejor puedan llegar a entenderse, y no como un intento de abrir sucursales o secciones de CLS en el extranjero" (Subrayado fuera del original).

La intención de los miembros de CLS no es exportar teorías, por dos razones sencillas: porque sus constructos teóricos son eminentemente locales -no hay construcción de grandes teorías generales con la virtualidad de ser aplicables a todos o a la mayoría de contextos posiblesy, como consecuencia de lo anterior, sus pretensiones no van más allá de la búsqueda de conocimiento, de compartir -dar y recibir-conocimientos similares a los suyos.

Este rasgo del movimiento es fundamental para comprender en qué medida las críticas externas tienen la suficiente fuerza y provienen del estereotipo construido alrededor, no sólo de este movimiento sino de las teorías críticas como corrientes alternativas, pues descansan, en la mayoría de las ocasiones, en este punto ${ }^{19}$. Naturalmente no se pretende con lo dicho atacar a quienes esgrimen estas opiniones, es comprensible que una persona que pretende elaborar una teoría aplicable al mayor número de personas y situaciones vea con desconfianza posturas que no se mueven por tal ambición.

Dicho lo anterior, de la revisión de la literatura sobre CLS es dable concluir que, pese a que en la mayoría de análisis se trata el tema de la "contradicción fundamental" ello se realiza a modo explicativo, descriptivo ${ }^{20}$ y en muchos casos como elementos de discursos políticos ${ }^{21}$ o netamente de análisis ideológico del derecho ${ }^{22}$, pero lo cierto es que sí se ha abordado su estudio, tanto en Europa como en Latinoamérica, pero no del modo o con la profundidad con que se ha hecho en el caso estadounidense.

\section{CONCLUSIÓN.}

Explicar el origen y rasgos característicos del movimiento CLS es una labor de especial complejidad, dado el carácter diverso y multidisciplinar de sus estudios.

Ante este panorama, lejos de dejarlo de lado, la labor de todo jurista intelectualmente inquieto habría de consistir en despojarse de prejuicios y etiquetas y adentrarse en el descubrimiento del todo o parte de este universo complejo llamado CLS, sin que ello signifique en modo alguno

19 Críticas sobre este punto se encuentran en LOSANO, M., La ley y la azada: Origenes $y$ desarrollo del derecho alternativo en Europa y Sudamérica, Derechos y Libertades, No. 8, 2000. P. 278

20 CASAMIGLIA, A., La retórica de CLS. Impresiones de un lector español, Doxa, No. 11, 1992. p. 295-310

21

22 BOVINO, A. y COURTIS, C., Por una dogmática conscientemente política. Desde otra mirada: textos de teoría, crítica del derecho, COURTIS, C. (comp), 2a ed, Eudeba, Buenos Aires, 2009. 
una aceptación acrítica de las consignas por ellos proclamadas, pero sí un conocimiento aproximativo, necesario para poder defenderlas o atacarlas, máxime cuando sus constructos críticos se dirigen precisamente contra modelos "tradicionales" o sus deformaciones, como sucede en el caso de CLS, directo heredero del realismo jurídico estadounidense, crítico del formalismo en boga durante los últimos años del siglo XIX y las primeras décadas del XX.

Sin duda alguna la construcción teórica de la o las contradicciones en el seno del liberalismo, en el campo jurídico, constituye un aporte a la ciencia jurídica contemporánea que ha de partir necesariamente de la necesaria conexión entre ideología política, moral y económica y derecho positivo.

El aporte del movimiento, particularmente desde la tesis de Kennedy, es meramente exploratorio, no ofrece una solución concreta. Pese a ello (la aparente inocuidad de la producción teórica) sí queda en el viento un llamado a la acción dirigido a quienes ejercen a diario el Derecho: que sean conscientes de la existencia de esas contradicciones y actúen en pro de aplicaciones que viren hacia el polo "débil", el altruismo, en favor de causas en los que sea indispensable.

Finalmente, el hecho de identificar como de izquierda al movimiento en su conjunto no quiere decir que propugne por la caída del liberalismo. Significa, por el contrario, comprender las estrategias de cambio que el propio sistema ofrece. La actuación de CLS en su conjunto pretende modificar aspectos estructurales del liberalismo sin que ello torne necesaria o ineludible una transformación de este modelo ideológico.

\section{BIBLIOGRAFÍA.}

Atienza, M. (2007). Una propuesta de Filosofía del Derecho para el mundo Latino. DOXA. Cuadernos de Filosofía del Derecho (30), pp. 661-663.

Bovino, A. y Courtis, C. (2009). Por una dogmática conscientemente política. En C. Courtis. (Comp) (2 ed), Desde otra mirada: textos de teoría crítica del derecho (pp. 303-342). Buenos Aires, Argentina: Eudeba.

Cárcova, C.M. (2009). Notas acerca de la Teoría Crítica del Derecho. En C. Courtis. (Comp) (2 ed), Desde otra mirada: textos de teoría crítica del derecho (pp. 19-39). Buenos Aires, Argentina: Eudeba.

Casamiglia, A. (1992). La retórica de CLS. Impresiones de un lector español, doxa, no. 11, 1992. (295-310)

Gordon, R. W. (2009). Nuevos desarrollos de la teoría crítica. En C. Courtis. (Comp) (2 ed.), Desde otra mirada: textos de teoría crítica del derecho (pp. 501-518). Buenos Aires, Argentina: Eudeba. 
. (2009). Cómo "descongelar" la realidad legal: una aproximación crítica al derecho. En C. Courtis. (Comp) (2 ed.), Desde otra mirada: textos de teoría crítica del derecho (pp. 519-548). Buenos Aires, Argentina: Eudeba.

Kennedy. D. (1979). The structure of Blackstone's Commentaries. Buffalo Law Review (205), pp. 211-212. Recuperado de http://duncankennedy. net/documents/photo\%20articles/the\%20structure\%20of\%20 blackstone_s\%20commentaries.pdf

- (2001)“Forma y Sustancia en la adjudicación del Derecho Privado”, Sociología Jurídica, Teoría y Sociología del Derecho en Estados Unidos, Villegas, M.(Ed), Universidad Nacional de Colombia, Bogotá

- (1992). Forma es sostanza nella giurisdizione di diritto privato, A. Carrino, (Trad). Napoli: Edizioni Scientifiche Italiane.

. (1992). Notas sobre la historia de CLS en Estados Unidos. Doxa (11), pp. 283-291.

- (2009). La educación legal como preparación para la jerarquía. En C. Courtis. (Comp) (2 ed.), Desde otra mirada: textos de teoría crítica del derecho (pp. 549-578). Buenos Aires, Argentina: Eudeba.

. (2009). ¿Son los abogados realmente necesarios?”. En C. Courtis. (Comp) (2 ed.), Desde otra mirada: textos de teoría crítica del derecho (pp. 579-593) Buenos Aires, Argentina: Eudeba.

Losano, M. (2000). La ley y la azada: orígenes y desarrollo del derecho alternativo en Europa y Sudamérica. Derechos y libertades (8), pp. 275-324.

Mesa, D.A. (2002). Fisuras en el pensamiento jurídico contemporáneo: el movimiento "Critical Legal Studies". Criterio jurídico 1 (2), pp. 129-159.

Núñez Vaquero, A. (2010). Teorías críticas del derecho: observaciones sobre el modelo de ciencia jurídica. Anuario de filosofía del Derecho. (26), pp. 413-434.

Pérez Lledó, J.A. (1996). El movimiento Critical Legal Studies”. Madrid: Tecnos.

- (1996). Teorías críticas del derecho. En E. Garzón Valdés, y F.J. Laporta. (Eds.), El derecho y la justicia (pp. 87-105). Madrid, España: Trotta. 
. (1995). Critical Legal Studies y el comunitarismo. Doxa (1718), pp. 137-164.

Treves, R. (1988). La sociología del derecho, orígenes investigaciones, problemas. Barcelona: Ariel. 